\title{
DRY SLIDING WEAR BEHAVIOR OF HYBRID METAL MATRIX COMPOSITES
}

\author{
Siddesh Kumar N G ${ }^{1}$, Ravindranath V $\mathbf{M}^{2}$, G S Shiva Shankar ${ }^{3}$ \\ ${ }^{I}$ Research Scholar, Department of Mechanical Engineering, Siddaganga Institute of Technology, Tumkur-572103, \\ Karnataka, India \\ ${ }^{2}$ Research Scholar, Department of Mechanical Engineering, Siddaganga Institute of Technology, Tumkur-572103, \\ Karnataka, India \\ ${ }^{3}$ Professor \& Head, Department of Mechanical Engineering, Siddaganga Institute of Technology, Tumkur- \\ 572103, Karnataka,India
}

\begin{abstract}
In the present study, the Al2219, Al2219/ $B_{4} C \& A l 2219 / B_{4} C / M o S_{2}$ hybrid composites are investigated under dry sliding wear test as for ASTM G 99-95 standard. Al 2219 base matrix reinforced with $B_{4} C$ \& mixture of $B_{4} C$ and $M o S_{2}$ are fabricated using stir casting technique. By using pin on disc apparatus the test was conducted by taking parameters like sliding distance, sliding velocity and loads. The result reveals that the addition of $B_{4} C$ slightly reduces wear rate of composites, further $B_{4} C$ and $M o S_{2}$ reinforcement decreases the wear rate of the hybrid composites and increases the wear resistance of the composites. The wear rate decreases with increasing the \% of $\mathrm{MoS}_{2}$. At a lower sliding velocity the wear rate decreases and as the sliding velocity increases the wear rate increases. As the sliding distances and load increases the wear rate drastically increases.
\end{abstract}

Keywords: Dry sliding wear, Stir casting, Hybrid composites, Wear rate, Wear resistance.

\section{INTRODUCTION}

Metal matrix composite materials are advanced materials, which combine tough metallic matrix with a hard ceramic or soft reinforcement to produce composite materials (Ref 1). These materials have superior properties compared to the monolithic materials and can be tail arable to a specific applications (Ref 1). The objective was to investigate which design parameter significantly affects the dry sliding wear. It shows that graphite particles are effective agents in increasing dry sliding wear resistance of $\mathrm{Al} / \mathrm{SiCp}$ composite (Ref 1 ). It is found that the addition of $\mathrm{SiCp}$ and graphite reinforcements increases the wear resistance of the composites (Ref 2).The wear rate decreases with the increase in $\mathrm{SiCp}$ reinforcement content. As speed increases, the wear rate decreases initially and then increases. The wear rate increases with the increase in load. Scanning electron microscopy micrographs of the worn surface are used to predict the nature of the wear mechanism (Ref 2). Abrasion is the principle wear mechanism for the composites at low sliding speeds and loads. At higher loads, the wear mechanism changes to delamination (Ref 2). S. Basavarajappa and G. Chandramohan (Ref 3) undertook an extensive review of dry sliding wear characteristics of aluminum alloy based composites, In this study, the effect of reinforcement volume fraction, reinforcement size, sliding distance (D), applied load (L), sliding speed (S), hardness of the counter face, and properties of the reinforcement phase, which influence the wear behavior of this group of composites, were examine din great detail. The sliding wear rate and wear behavior are reported to be influenced by various wear parameters (Ref 3).S. Basavarajappa and G. Chandramohan work was found that $\mathrm{SiCp}-\mathrm{Gr}$ (graphite)reinforced composites exhibit less volume loss when compared with SiCp-reinforced composites. Sliding speed is the most significant factor affecting wear behavior followed by $\mathrm{L}$ and $\mathrm{D}$. The effect of interactions between the $\mathrm{S}$ and the $\mathrm{L}$ is more pronounced in $\mathrm{SiCp}-\mathrm{Gr}$ composites (Ref 3).V.C.Uvaraja, N. Natarajan found that the wear resistance of the composites are higher, further the $\mathrm{SiC}$ contributed significantly in improving the wear resistance of Al7075-SiC$\mathrm{B}_{4} \mathrm{C}$ composites \& the coefficient of friction of specimen decreases with increasing volume content of reinforcements(Ref 4).S. Suresha, B.K. Sridhara investigates the influence of addition of graphite $(\mathrm{Gr})$ particulates as a second reinforcement on the tribological behaviour of aluminium matrix composites reinforced with silicon carbide (SiC) particulates. Dry sliding wear tests have been performed to study the influence of Gr particulates, load, sliding speed and sliding distance on the wear of hybrid composite [5] .Load and sliding distance show a positive influence on wear implying increase of wear with increase of either load or sliding distance or both[5]. Where as speed shows a negative influence on wear indicating decrease of wear with increase of speed. Interactions among load, sliding speed and sliding distance are noticed in hybrid composites and this may be attributed to the addition of Gr particulates[5].V. C. Uvaraja 
while investigating parameters such as applied load, sliding speed, percentage of reinforcement content and sliding distance on the dry sliding wear of 6061 aluminium with $\mathrm{SiC}$ and $\mathrm{B}_{4} \mathrm{C}$ particulate reinforced composite[6]. The hardness of the specimen at room temperature was also measured before the wear test by Rockwell hardness test machine. As the volume fraction of $\mathrm{SiC}$ and $\mathrm{B}_{4} \mathrm{C}$ reinforcement increases, the magnitude of hardness also increases [6]. Hybrid composite sample with $10 \mathrm{wt}$. \% $\mathrm{SiC}$ and $3 \mathrm{wt} \% \mathrm{~B}_{4} \mathrm{C}$ composition have better tribological properties. The reinforcement of Al 6061 alloy with $\mathrm{SiC}$ and $\mathrm{B}_{4} \mathrm{C}$ particulates up to a volume fraction of 5 to 15 wt. \% has marked effect on wear rate. The wear rate and coefficient of friction decrease with increasing volume fraction of reinforcements [6].N. Radhika, R. Subramanian, S. Venkat Prasat Investigation to find the influence of applied load, sliding speed and sliding distance on wear rate, as well as the coefficient of friction during wearing process was carried out using ANOVA and regression equations for each response were developed [7]. Objective of the model was chosen as 'smaller the better' characteristics to analyse the dry sliding wear resistance [7]. Incorporation of graphite as primary reinforcement increases the wear resistance of composites by forming a protective layer between pin and counter face and the inclusion of alumina as a secondary reinforcement also has a significant effect on the wear behaviour[7].S. Suresha, B.K. Sridhara have investigated the dry sliding wear behaviour of Al matrix composites reinforced with $\mathrm{Gr}$ and $\mathrm{SiC}$ particulate up to $10 \%$, to study the effect of $\%$ reinforcement, load, sliding speed and sliding distance on stir cast $\mathrm{Al}-\mathrm{SiC}-\mathrm{Gr}$ hybrid composites, $\mathrm{Al}-\mathrm{Gr}$ and $\mathrm{Al}-\mathrm{SiC}$ composites[8].Al-SiC composites, clearly indicating that hybrid composites exhibit better wear characteristics. Increase of speed reduces wear and increase of either load or sliding distance or both increases wear. Statistical analysis has revealed interactions among load, sliding speed and sliding distance in composites with $\mathrm{Gr}$ particulates[8].P.R.S. Kumar, S. Kumaran, T. Srinivasa Rao, S. Natarajan studied The effect of fly ash particulate on high temperature dry sliding wear resistance of AA6061, developed by powder metallurgy and hot extrusion, was studied. The dry sliding wear behavior of the prepared composite was investigated by using pin-on-disc method [9].AA6061-fly ash composites in T6 condition have exhibited better wear behavior compared to the matrix alloy at room and high temperatures. This is due to the uniform distribution of hard fly ash particles. Significant result of this work is that the composites do not suffer from mild-to-severe transition wear up to $300{ }^{\circ} \mathrm{C}$.This is attributed to the subsurface hardening effect of fly ash particles [9]. Instead, the AA6061 matrix alloy has exhibited mild-to-severe transition wear beyond $200{ }^{\circ} \mathrm{C}$ due to severe plastic deformation of matrix phase[9].W. Ma, J. Lu, B. Wang Investigates $\mathrm{Cu}$-graphite composite fabricated by powder metallurgy art is no longer novel material. However, it might be a versatile self-lubricating material sliding against different metals and alloys. The friction and wear tests were conducted on a pin-on-disk tribo-meter. Tribological performance of $\mathrm{Cu}-$ graphite composite strongly depended on its counterpart materials. $\mathrm{Cu}$-graphite composite could provide friction reduction in sliding against 2024 and Ti6Al4V.Cu-graphite composite was a good self-lubricating material in sliding against AZ91D at low speeds but not at 0.25 and $0.50 \mathrm{~m} / \mathrm{s}$. Wear mechanism of $\mathrm{Cu}-\mathrm{Gr}$ composite was related to the transfer, counter-transfer, mechanical mixing and tribooxidation at tribo-interface. Sliding speed had influences on tribo-interface and there by wear mechanism. Finally, the effects of naturally occurred oxide film and sliding speed were discussed.

An attempt is made in the present work to study the wear behaviour of Al 2219 alloy and Al 2219/ $\mathrm{B}_{4} \mathrm{C} / \mathrm{MoS}_{2}$ composites. The effect of sliding velocity, load, and sliding distance on the wear behaviour of the composites is studied.

\section{EXPERIMENTATION}

\subsection{Materials}

In the present investigation, Aluminium 2219 alloy is used as a matrix and composition is shown in Table1.A12219 is chosen because it is used in aerospace and high temperature applications due to its characteristics such as excellent weld ability and its light weight. In our study the reinforcement material i.e. Boron Carbide and Molybdenum disulfide is taken.

Table-1: Constituent of Al2219in Weight \%

\begin{tabular}{|l|l|l|l|l|l|l|l|l|l|l|}
\hline $\begin{array}{l}\text { Ele } \\
\text { ment } \\
\text { s }\end{array}$ & Mg & Si & $\begin{array}{l}\mathrm{C} \\
\mathrm{u}\end{array}$ & $\begin{array}{l}\mathrm{Z} \\
\mathrm{r}\end{array}$ & $\begin{array}{l}\mathrm{F} \\
\mathrm{e}\end{array}$ & $\begin{array}{l}\mathrm{Z} \\
\mathrm{n}\end{array}$ & $\mathrm{Ti}$ & $\mathrm{V}$ & $\begin{array}{l}\mathrm{Z} \\
\mathrm{n}\end{array}$ & $\mathrm{Al}$ \\
\hline $\begin{array}{l}\text { Wei } \\
\text { ght }\end{array}$ & 0.02 & 0. & 5. & 0. & 0. & 0. & 0. & 0. & 0. & Rema \\
in\% & 2 & $8-$ & $1-$ & 3 & 1 & 02 & 05 & 1 & ining \\
& & 0 & 6. & 0. & 0 & 0 & - & - & $\mathrm{M}$ & \\
& & $\mathrm{M}$ & 8 & 2 & $\mathrm{M}$ & $\mathrm{M}$ & 0. & 0. & $\mathrm{ax}$ & \\
$\mathrm{ax}$ & & 5 & $\mathrm{ax}$ & $\mathrm{ax}$ & 1 & 15 & & \\
\hline
\end{tabular}

\subsection{Fabrication of Composites}

The composites are prepared by using stir casting technique and composite furnace is used for fabrication is shown in fig1.During the present work the four different compositions are fabricated for $\mathrm{Al}$ alloy, $\mathrm{Al}$ alloy $+3 \%$ by wt $\mathrm{B} 4 \mathrm{C}, \mathrm{Al}$ alloy $+3 \%$ by wt $\mathrm{B} 4 \mathrm{C}+3 \%$ by wt MoS2 \&Al alloy $+3 \%$ by wt $\mathrm{B} 4 \mathrm{C}+4 \%$ by wt MoS2 under similar conditions. The Al2219 alloy is heated above its melting temperature (7500-8000C) and allow them to completely liquid in silica crucible. The mixture of $\mathrm{B} 4 \mathrm{C}$ and $\mathrm{MoS} 2$ particles are added into molten metal and particles starts distributed around the matrix material (Al alloy).After adding reinforcement material stirring is carried out for $5 \mathrm{~min}$ at a speed or 350 to $400 \mathrm{rpm}$, finally slurry was poured to cast iron mould \& the desired ingots will be obtained. 


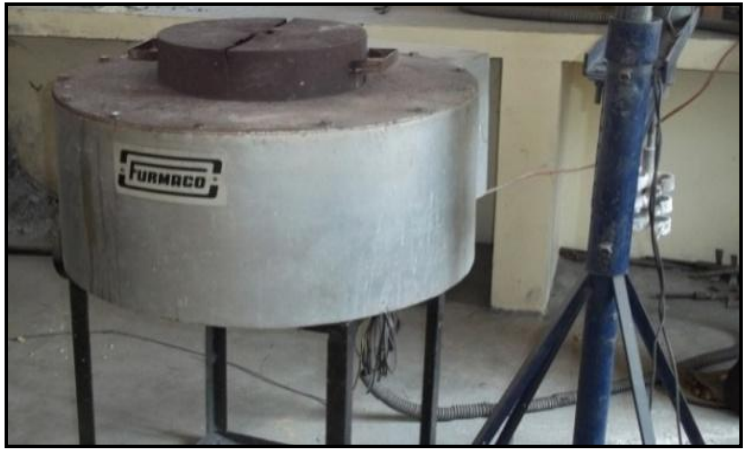

Fig-1: Composite Furnaces

\section{EXPERIMENTAL PROCEDURE}

The desired ingots obtained from casting were machined to a diameter of $12 \mathrm{~mm}$ and $30 \mathrm{~mm}$ length and pins are rubbed in order to ensure hardness of specimen with 200, 400, 600 and 800 grit sizes $\mathrm{SiC}$ paper. Test was conducted by using pin on disc apparatus it is shown in fig.2. Initially weight of the specimen is measured with the help of electronic weighing machine. The test was conducted for different load, sliding distance \& sliding velocity. After the test final weight of specimen is noted down and in order to remove any debris specimen is cleaned with acetone. The wear rate is calculated by using formula.

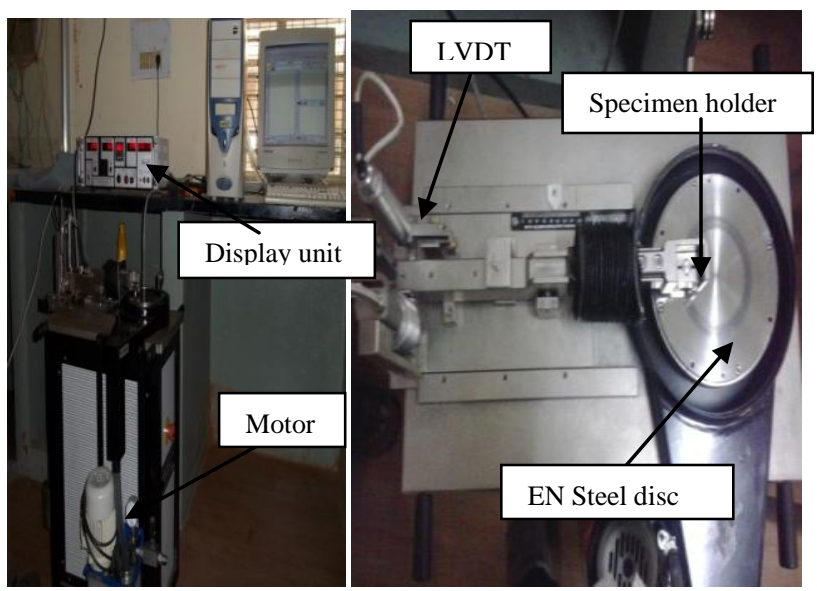

Fig.2: Pin on disc apparatus

\section{RESULTS AND DISCUSSIONS}

\subsection{Micro Structural Study}

The micrographs are captured by using optical microscope. Fig 3(a) shows microstructure of Al 2219 alloy where no reinforcement particles are seen. Fig 3(b) shows the microstructure of $\mathrm{Al} 2219+3 \% \mathrm{~B}_{4} \mathrm{C}$, where the distribution of $\mathrm{B}_{4} \mathrm{C}$ particles are fairly uniform throughout the matrix. Fig 3(c) \& 3(d) shows $\mathrm{Al} 2219+3 \% \mathrm{~B}_{4} \mathrm{C}+3 \% \mathrm{MoS}_{2} \& \mathrm{Al} 2219+3 \%$
$\mathrm{B}_{4} \mathrm{C}+4 \% \mathrm{MoS}_{2}$ where the uniform distribution of $\mathrm{MoS}_{2}$ (black region) around $\mathrm{B}_{4} \mathrm{C}$ particles throughout the matrix.

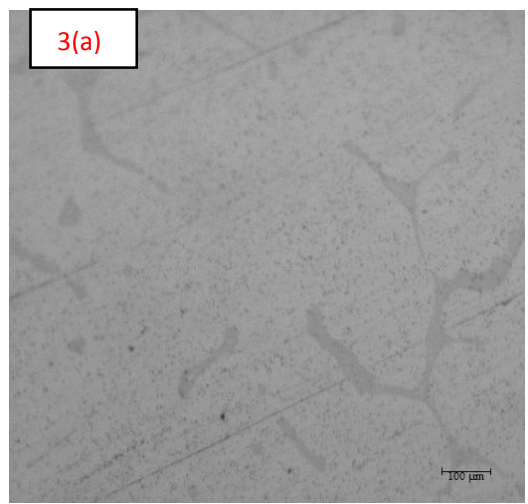

Fig -3(a): Optical micrograph of Al2219 alloy

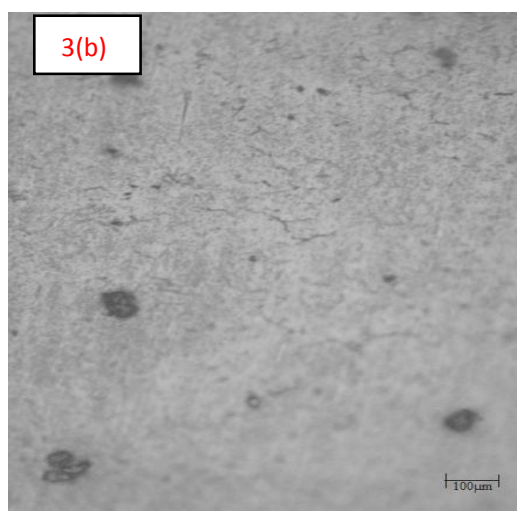

Fig -3(b): Optical micrograph of $\mathrm{Al} 2219+3 \% \mathrm{~B}_{4} \mathrm{C}$

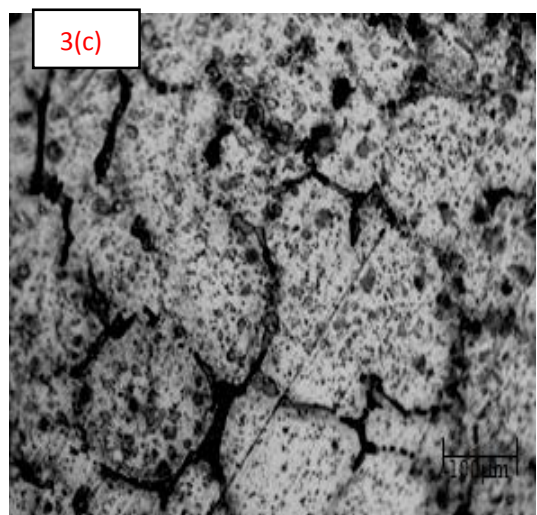

Fig-3(c): Optical micrograph of $\mathrm{Al} 2219+3 \% \mathrm{~B}_{4} \mathrm{C}+3 \% \mathrm{MoS}_{2}$ 


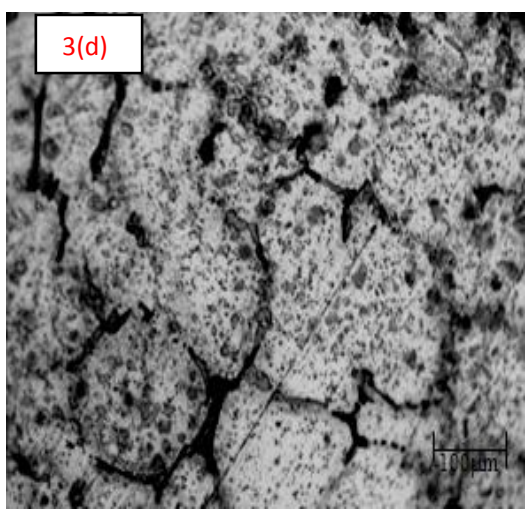

Fig-3(d): Optical micrograph of Al 2219+3\% $\mathrm{B}_{4} \mathrm{C}+4 \% \mathrm{MoS}_{2}$

\subsection{Hardness}

Vickers micro hardness test was conducted by using Zwick Vickers micro hardness tester. The test was carried out for a load of $50 \mathrm{~g} \&$ for a period of $10 \mathrm{sec}$. The result reveals that hardness of the composite is higher than that of non reinforced alloy. Higher strength of the composites is due to the addition of $\mathrm{B} 4 \mathrm{C} \& \mathrm{MoS}_{2}$ particles acts as the obstacles to the motion of dislocation. From the fig 4 it can clearly shown that hardness is minimum for $\mathrm{Al}$ alloy \& maximum for $\mathrm{Al} 2219+3 \% \mathrm{~B}_{4} \mathrm{C}+\mathrm{MoS}_{2}$.

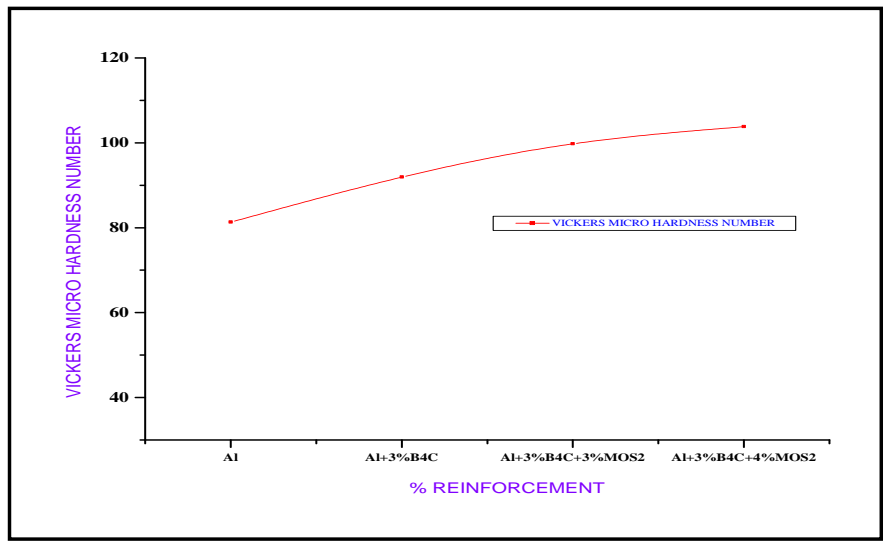

Fig-4: Change in Hardness of the material with percentage reinforcement

\subsection{Dry Sliding Wear Test}

\subsubsection{Effect of Load}

The fig 5 clearly shows the variation of wear rate under different loading condition at a speed of $3.768 \mathrm{~m} / \mathrm{s}$ and a constant sliding distance $1500 \mathrm{~m}$. The wear rate is more for $\mathrm{Al} 2219$ and lesser for addition of $\mathrm{B}_{4} \mathrm{C}$ and $\mathrm{MoS}_{2}$ prepared composites. Al2219 is having a nature of smooth surface undergoes more wear rate but in prepared composite hard $\mathrm{B}_{4} \mathrm{C}$ and $\mathrm{MoS}_{2}$ particles resist the applied load and forms lesser wear rate. As the applied load increases the wear rate also increases because pressure at pin and disc interface become more.

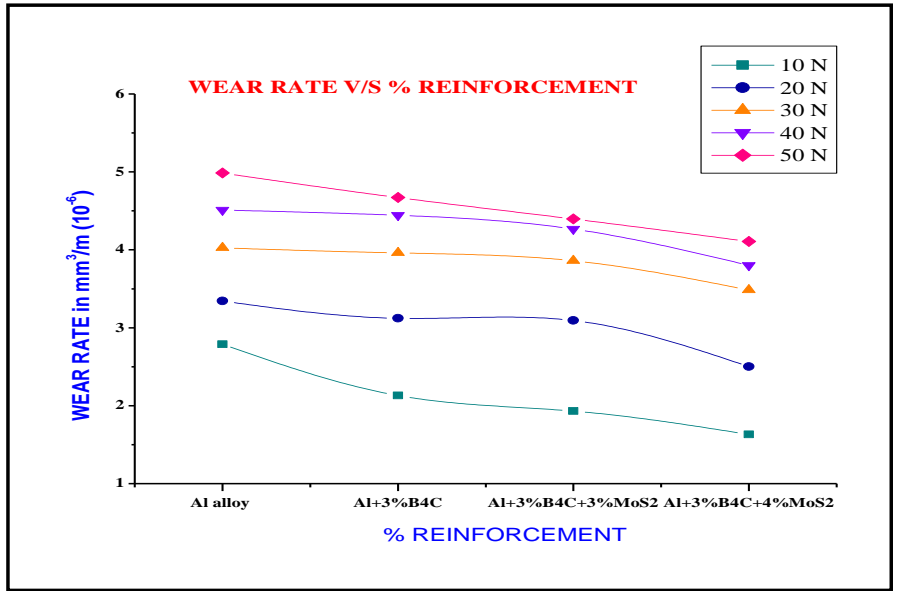

Fig-5: Variation of wear rate with wt $\%$ of reinforcement for different Load at a constant sliding velocity of $3.77 \mathrm{~m} / \mathrm{s}$.

\subsubsection{Effect of Sliding Distance}

The fig.6 clearly shows the variation of wear rate under different sliding distance at a sliding velocity of $3.768 \mathrm{~m} / \mathrm{s}$ and a constant load of $30 \mathrm{~N}$. The wear rate is more for $\mathrm{Al} 2219$ \& less for prepared hybrid composites because due to increase in hardness of composites as compared to Al2219. As the sliding distance increases the wear rate increases and as the \% of reinforcement increases wear rate decreases because $\mathrm{B}_{4} \mathrm{C}$ and $\mathrm{MoS}_{2}$ particles are crushed and form work harden layer between pin and the counter face thus reduces the wear rate of composites.

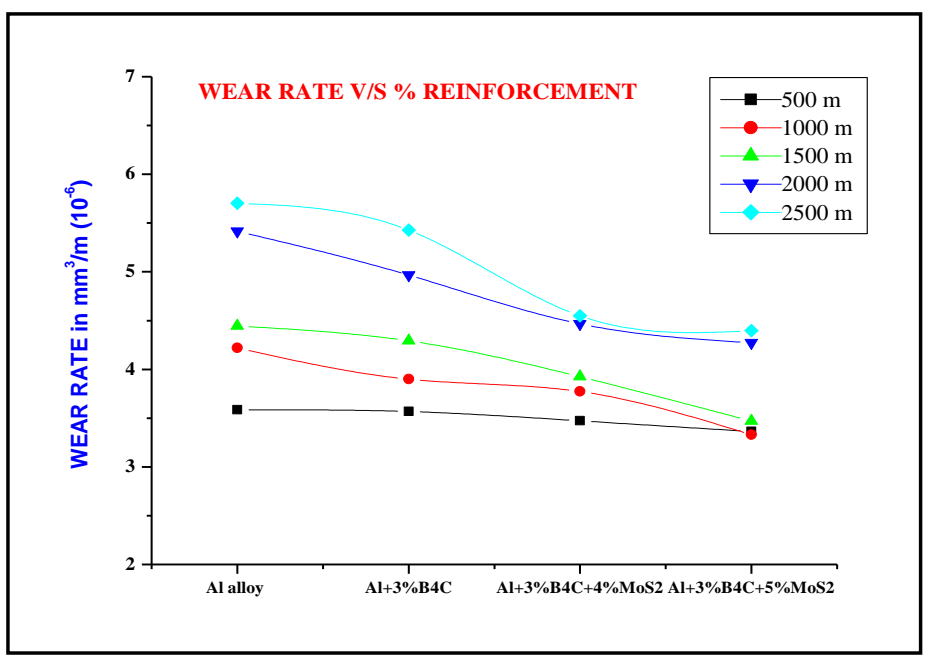

Fig-6: Variation of wear rate with wt \% of reinforcement for different sliding speed at a constant Load of $30 \mathrm{~N} \&$ at a sliding Distance of $1500 \mathrm{~m}$. 


\subsection{Effect of Sliding Velocity}

The fig 4.33 clearly shows the variation of wear rate under different sliding velocity conditions at a sliding distance of $1500 \mathrm{~m} \&$ load of $30 \mathrm{~N}$. The wear rate is more for Al 2219\& lesser for prepared composites. As the \% of reinforcement material is added the wear rate reduces. The wear rate is reduced due to the presence of $\mathrm{B}_{4} \mathrm{C} \& \mathrm{MoS}_{2}$ particles spreads on the surface of the pin $\&$ formation of protecting layer between pin \& disc. So the prepared composite has lesser wear rate when compared to $\mathrm{Al} 2219$.

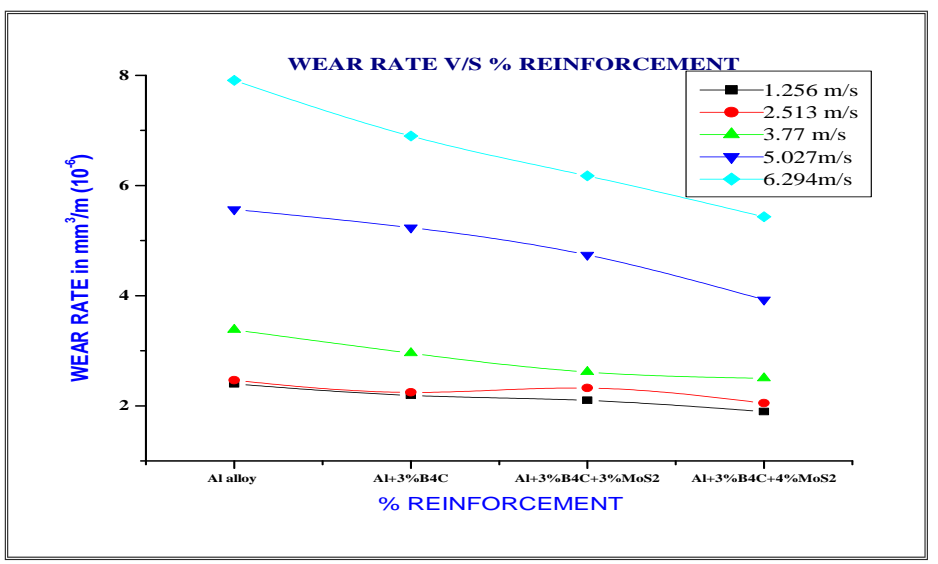

Fig-7: Variation of wear rate with wt \% of reinforcement for different sliding speed at a constant Load of $30 \mathrm{~N} \&$ at a sliding Distance of $1500 \mathrm{~m}$.

\section{CONCLUSIONS}

The hybrid composites prepared by stir casting technique for Al 2219 reinforced with hard $\mathrm{B}_{4} \mathrm{C}$ \& solid lubricant $\mathrm{MoS}_{2}$ particles successfully. The microstructure of Al2219 reinforced $3 \% \quad \mathrm{~B}_{4} \mathrm{C}$ shows fairly uniform distribution throughout matrix \& for Al $2219+3 \% \mathrm{~B}_{4} \mathrm{C}+3 \% \quad \mathrm{MoS}_{2}$ \& $\mathrm{Al} 2219+3 \% \mathrm{~B}_{4} \mathrm{C}+4 \% \mathrm{MoS}_{2}$ shows uniform distribution of $\mathrm{MoS}_{2}$ around $\mathrm{B}_{4} \mathrm{C}$ particles. Hardness increases with increasing $\%$ of reinforcements because due to condition of $\mathrm{B}_{4} \mathrm{C} \& \mathrm{MoS}_{2}$ particles cuts as the obstacles to motion of dislocation. The wear rate is more for $\mathrm{Al} 2219$ \& slightly lesser for $\mathrm{Al} 2219+3 \% \mathrm{~B}_{4} \mathrm{C}$.The addition of $\mathrm{B}_{4} \mathrm{C} \& \mathrm{MoS}_{2}$ particles decreases the wear rate $\&$ by increasing the $\%$ of $\mathrm{MoS}_{2}$ the wear rate of composites increases.A12219 is having a nature o smooth surface undergoes more wear rate but in prepared composite hard $\mathrm{B}_{4} \mathrm{C}$ and $\mathrm{MoS}_{2}$ particles resist the applied load and forms lesser wear rate. As the sliding distance increases the wear rate increases and as the \% of reinforcement increases wear rate decreases because $\mathrm{B}_{4} \mathrm{C}$ and $\mathrm{MoS}_{2}$ particles are crushed and form work harden layer between pin and the counter face. As the \% of reinforcement material is added the wear rate reduces. The wear rate is reduced due to the presence of $\mathrm{B}_{4} \mathrm{C} \& \mathrm{MoS}_{2}$ particles spreads on the surface of the pin $\&$ formation of protecting layer between pin \& disc

\section{ACKNOWLEDGEMENTS}

We express our first and fore most pranamas to his Holiness Dr.Sree Sree Shivakumara Swamigalu, President, SSES. The authors acknowledge with thanks to Director Dr.M.N.Channabasappa and Principal Dr.Shivakumaraiah who made this Endeavour possible and also express our gratitude and indebtedness to Siddaganga Institute of Technology, Tumkur, for providing us an opportunity to undergo research work successfully.

\section{REFERENCES}

[1]. S. Basavarajappa, G. Chandramohan, J. Paulo Davim., "Application of Taguchi techniques to study dry sliding wear behaviour of metal matrix composites Materials and Design",28 (2007) 1393-1398.

[2]. S. Basavarajappa, G. Chandramohan, K. Mukund, M. Ashwin, and M. Probes., "Dry Sliding Wear Behaviour of Al 2219/SiCp-Gr Hybrid Metal Matrix Composites", JMEPEG (2006) 15:668-674.

[3]. S.Basavarajappa and G. Chandramohan., "Dry Sliding Wear Behaviour of Metal Matrix Composites", A Statistical Approach,-JMEPEG (2006) 15:656-660.

[4]. V.C.Uvaraja, N. Natarajan., "Comparison on Al6061 and Al7075 alloy with sic and $\mathrm{B}_{4} \mathrm{C}$ reinforcement hybrid metal matrix composites", IJART, Vol.2 Issue 2, 2012, 1- 12 ISSN NO: 66023127.

[5]. Suresh, B.K. Sridhara., "Effect of addition of graphite particulates on the wear behaviour in aluminium-silicon carbide-graphite composites", Materials and Design 31 (2010) 1804-1812.

[6].V.C.Uvaraja, N.Natarajan.,"Tribological Characterization of Stir-Cast Hybrid Composite Aluminium 6061 Reinforced with Sic and B ${ }_{4}$ C Particulates", ISSN 1450-216X Vol.76 No.4 (2012), pp.539-552.

[7]. Radhika, R. Subramanian, S. Vencor Prasat., "Tribological Behaviour of Aluminium/Alumina/Graphite Hybrid Metal Matrix Composite Using Taguchi's Techniques", Vol. 10, No.5, pp.427-443, 2011 jmmce.org.

[8].S.Suresha, B.K.Sridhara."Wear characteristic of hybrid aluminium matrix composites reinforced with graphite and silicon carbide particulates", Composites Science and Technology 70 (2010) 1652-1659.

[9]. P.R.S. Kumar, S. Kumaran, T. Srinivasa Rao, S. Natarajan.,"High temperature sliding wear behaviour of pressextruded AA6061/fly ash composite", Materials Science and Engineering A 527 (2010) 1501-1509.

[10]. Maa, J. Lua, and B. Wanga."Sliding friction and wear of $\mathrm{Cu}$-graphite against 2024, AZ91D and Ti6Al4V at different speeds", Wear 266 (2009) 1072-1081 